\title{
The Biological Effects of Combining Metals in a Posterior Spinal Implant: In Vivo Model Development Report of the First Two Cases
}

\author{
Christine L. Farnsworth, ${ }^{1}$ Peter O. Newton, ${ }^{1,2}$ Eric Breisch, ${ }^{3}$ Michael T. Rohmiller, \\ Jung Ryul Kim, ${ }^{4}$ and Behrooz A. Akbarnia ${ }^{2,5}$ \\ ${ }^{1}$ Division of Orthopedics, Rady Children's Hospital-San Diego, 3020 Children's Way, MC 5054, San Diego, CA 92123, USA \\ ${ }^{2}$ Department of Orthopaedic Surgery, University of California San Diego, San Diego, CA 92103, USA \\ ${ }^{3}$ Department of Pathology, Rady Children's Hospital San Diego, San Diego, CA 92123, USA \\ ${ }^{4}$ Department of Orthopaedic Surgery, Chonbuk National University Hospital, Jeonbuk 561-712, Republic of Korea \\ ${ }^{5}$ San Diego Center for Spinal Disorders, La Jolla, CA 92037, USA
}

Correspondence should be addressed to Christine L. Farnsworth; cfarnsworth@rchsd.org

Received 17 September 2013; Revised 8 January 2014; Accepted 11 January 2014; Published 26 February 2014

Academic Editor: Federico Canavese

Copyright (C) 2014 Christine L. Farnsworth et al. This is an open access article distributed under the Creative Commons Attribution License, which permits unrestricted use, distribution, and reproduction in any medium, provided the original work is properly cited.

\begin{abstract}
Study Design. Combinations of metal implants (stainless steel (SS), titanium (Ti), and cobalt chrome (CC)) were placed in porcine spines. After 12 months, tissue response and implant corrosion were compared between mixed and single metal junctions. Objective. Model development and an attempt to determine any detriment of combining different metals in posterior spinal instrumentation. Methods. Yucatan mini-pigs underwent instrumentation over five unfused lumbar levels. A SS rod and a Ti rod were secured with Ti and SS pedicle screws, SS and Ti crosslinks, SS and CC sublaminar wires, and Ti sublaminar cable. The resulting 4 SS/SS, 3 Ti/Ti, and 11 connections between dissimilar metals per animal were studied after 12 months using radiographs, gross observation, and histology (foreign body reaction (FBR), metal particle count, and inflammation analyzed). Results. Two animals had constructs in place for 12 months with no complications. Histology of tissue over SS/SS connections demonstrated 11.1 \pm 7.6 FBR cells, $2.1 \pm$ 1.7 metal particles, and moderate to extensive inflammation. Ti/Ti tissue showed $6.3 \pm 3.8 \mathrm{FBR}$ cells, $5.2 \pm 6.7$ particles, and no to extensive inflammation (83\% extensive). Tissue over mixed components had $14.1 \pm 12.6$ FBR cells and $13.4 \pm 27.8$ particles. Samples surrounding wires/cables versus other combinations demonstrated FBR (12.4 \pm 13.5 versus $12.0 \pm 9.6$ cells, $P=0.96)$, particles (19.8 \pm 32.6 versus $4.3 \pm 12.7, P=0.24$ ), and inflammation ( $50 \%$ versus $75 \%$ extensive, $P=0.12$ ). Conclusions. A nonfusion model was developed to study corrosion and analyze biological responses. Although no statistical differences were found in overlying tissue response to single versus mixed metal combinations, galvanic corrosion between differing metals is not ruled out. This pilot study supports further investigation to answer concerns when mixing metals in spinal constructs.
\end{abstract}

\section{Introduction}

Metal spinal implants are not routinely removed, so corrosion over potentially several decades is a concern $[1,2]$. Any movement between metal surfaces, even on the microscopic level, results in etching of the softer surface and often produces wear debris. As the metallic debris oxidizes or corrodes, the particles harden, causing abrasion and more severe etching, resulting in a cycle of implant destruction. Corrosion complications in spinal surgery are related to both loss of implant integrity and biological responses and include infection, toxicity, deterioration of construct strength, and pain [3]. Spine surgeons have experience with visualizing debris and darkened tissue surrounding implants that have been removed routinely or due to a clinical concern [4-6]. There is certainly the potential of motion existing between metal components of a construct designed to stabilize a spine following surgical intervention, both before a bony fusion is complete and following bony healing. Concern of corrosion increases when mixing two different metals in a biological, 
electrolytic system where an oxidation reaction, boosted by temperature, creates the ideal environment for galvanic corrosion. With the increased clinical use of titanium (Ti) and potential use of Ti in combination with existing stainless steel (SS) implants, there is increased concern amongst surgeons of galvanic corrosion related to mixing these metal classes. In addition to the concern of fretting corrosion caused by micromotion between components, galvanic corrosion could potentially occur within a spinal implant where SS or chromium (serving as an anode) is in physical contact with Ti (the cathode) within an in vivo environment acting as a conducting electrolyte.

Clinical studies of corrosion of explanted spinal implants as well as animal model studies including tissue response at metal junctions have been done [5-12]. A general consensus seems to have been reached that SS implants have a more significant risk of corrosion than Ti; however, in these investigations all components were of a single metal (SS or Ti). Clinical studies and reviews still tend to advise against mixing metal materials and those with different surface finishes [11, 13]. In vitro studies of spinal constructs including both SS and Ti components following cyclical mechanical testing at biological temperatures in either serum or saline solutions suggest that corrosion in SS-Ti interfaces is the same [14] or even less [15] than in SS only. Other in vitro studies using similar biological environments have been shown to produce similar levels of corrosion in mixed metal components as in an in vivo environment [16]. However, in vitro studies cannot elucidate any information about tissue response to corrosion. Metal particulate (Ti) placed at the level of a spinal arthrodesis in an in vivo model (rabbit) has been shown to increase cellular inflammatory response, osteoclastic response, and osteolysis $[9,10]$; however, implants were not available to be evaluated for corresponding corrosion. There are no known studies showing corrosive effects on implants at metallic junctions and overlying in vivo tissue response to spinal implants composed of different metals. This study evaluated implants and the surrounding tissue of mixed versus single metal combinations (Ti and SS rods with SS, cobalt chrome (CC) and Ti sublaminar wires, SS and Ti cross links, and SS and Ti screws with SS and Ti connectors) twelve months following posterior spinal instrumentation using a Yucatan minipig model.

\section{Materials and Methods}

The institutional animal care and use committee approved and provided oversight for this study. Seven Yucatan minipigs approaching the age of skeletal maturity (12-14 months of age, $26-49 \mathrm{~kg}$, and two female and five male) were acquired and housed for at least one week preoperatively to acclimate. Mini-pigs were housed both pre- and postoperatively in controlled climate inside individual pens.

2.1. Surgical Protocol. To assure adequate surgical analgesic plasma levels, twelve to nineteen hours prior to surgery, a patch of skin between the shoulder blades of the animal was clipped, swabbed with alcohol, and a fentanyl transdermal patch (100 micrograms/hour) was affixed. The patch was left in place until three to four days post-op. Any breakthrough pain was treated with buprenorphine, $0.01 \mathrm{mg} / \mathrm{kg}$ IM.

Animals were deprived from solid food for twelve to fifteen hours prior to surgery (water remained available ad lib) to decrease aspiration risk. The mini-pigs were weighed immediately prior to the surgical procedure and sedated by an intramuscular (IM) injection into the neck muscles behind an ear of a cocktail of $25 \mathrm{mg} / \mathrm{kg}$ ketamine, $2 \mathrm{mg} / \mathrm{kg}$ xylazine, and $0.05 \mathrm{mg} / \mathrm{kg}$ atropine. Once sedated, the animals were placed prone for dorsoventral (DV) and laterally recumbent on the left side for lateral radiographs, and then they were shaved over the lower back and grounding pad site. Preoperative antibiotics consisted of IM cefazolin (1 gram) given 30 minutes prior to surgery for wound prophylaxis. A maintenance infusion of lactated Ringer's solution was given at a rate of $5-10 \mathrm{cc} / \mathrm{kg} / \mathrm{hr}$ through an over-the-needle catheter placed in an ear vein. Induction began with propofol, $2 \mathrm{mg} / \mathrm{kg}$, administered through the intravenous line. Direct laryngoscopy to intubate the trachea using a 6.0 or $6.5 \mathrm{~mm}$ inner diameter, cuffed endotracheal tube was performed. After securing the endotracheal tube, mechanical ventilation was started and anesthesia was maintained with volatilized isoflurane (1.5-3\%). Following this, each animal was positioned in the prone (or dorsal) position and the lower back prepped with betadine. A transcutaneous pulse oximeter was applied to the tongue or ear, a rectal probe was inserted to monitor temperature, and a heating blanket was applied to maintain normothermia. Heart rate, oxygen saturation, and temperature were constantly monitored.

Following achievement of an adequate level of anesthesia, a posterior approach was used to visualize the lower thoracic and entire lumbar spine using sterile surgical techniques. Instrumentation sites were prepared over five levels. All SS and Ti implants were commercially available for spine surgery (DePuy Spine, Inc, Raynham, MA), but the CC wires were experimental. The appropriate rod length was measured and one $4.75 \mathrm{~mm}$ Ti rod and one $4.75 \mathrm{~mm}$ SS rod were cut and placed adjacent to the spinous process (SS on the left and $\mathrm{Ti}$ on the right side, Figure 1, where L1 refers to the most proximal surgical vertebral level and L5, the most distal). No attempt was made to bend the rods to match the natural sagittal contour of the spines. Rods were secured in place with the following construct: Ti pedicle screw $(4.75 \mathrm{~mm} \times$ $25 \mathrm{~mm}$ long) at Level 1 with Ti offset connector on the left and SS connector on the right, SS cross link at Level 12 , SS sublaminar wire (18 gauge, or $1.0 \mathrm{~mm}$ diameter) at Level 2, a single Ti sublaminar cable $(1.0 \mathrm{~mm}$ diameter) at Level 3, CC sublaminar wire (MP35N, $1.0 \mathrm{~mm}$ diameter) at Level 4, Ti cross link at Level 4-5, and SS pedicle screw $(4.75 \mathrm{~mm} \times 25 \mathrm{~mm}$ long) at Level 5 . All sublaminar wires and cables were placed from distal to proximal around the lamina. This construct resulted in 4 SS/SS connections, 3 $\mathrm{Ti} / \mathrm{Ti}$ connections, and 11 connections between dissimilar metals per animal. No fusion was done in order to maximize any possible corrosive responses.

Following surgery, administration of anesthesia was terminated and the animal recovered in a padded pen. Radiographs were taken as detailed below. Once the animal 


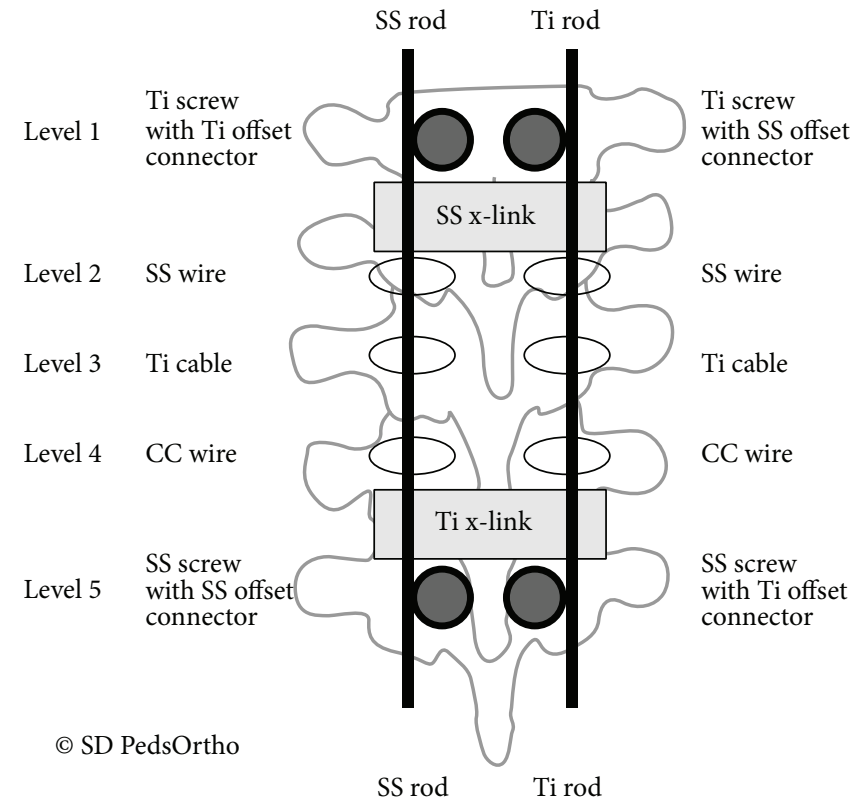

FIGURE 1: Schematic depiction of implanted construct.

exhibited sufficient tone and was breathing independently, the endotracheal tube was removed. Postoperative antibiotics consisted of sulfamethoxazole and trimethoprim (SMZ), $50 \mathrm{mg} / \mathrm{kg}$ PO BID for 5 days post-op. When the implants had been in place for one year, the animal were weighed, sedated as detailed above, and euthanized with Beuthanasia$\mathrm{D}$ delivered intravenously in a dose of $90 \mathrm{mg} / \mathrm{kg}$ of phenobarbital. The entire lumbar spine along with the implants was harvested en bloc.

2.2. Radiographic Analysis. Plain radiographs (DV and lateral) were taken immediately prior to surgery (following sedation), immediately following surgery while still under surgical anesthesia, at 3, 6, 9, and 12 months post-op (of sedated animals) and following harvest. The location and integrity of the implants, along with any post-op fusion, were evaluated for each of the instrumented segments. Cobb angles of the instrumented regions were measured from lateral radiographs at each time point. Also, the distance between each rod and sublaminar wires/cable (rod-to-wire distance) was measured from the immediate postoperative lateral radiographs and analyzed to determine any trend in risk for neurological deficit. To eliminate the radiographic magnification effect, rod diameter $(4.75 \mathrm{~mm})$ served to calibrate all measurements.

2.3. Gross Observation. Photographs were taken of the entire spine with overlying tissue and qualitative observations recorded about the integrity of the tissue, color of the tissue and rod-wire contact areas, presence of loose metallic material, and condition of the wires (intact or broken, eroded, etc.). Overlying tissue, screw connectors, and sublaminar wires were removed from each $\mathrm{Ti}$ and SS rod at each level. Both rods from each spine had photographs taken at each level of contact with a metal component and qualitative observations were recorded (coloring, etching of the surface, and loose material).

2.4. Histological Analysis. Tissue samples directly overlying the rods alone and at each metallic contact were dissected away from eleven locations over the SS rod and eleven locations over the Ti rod, taking care to avoid any contact of scalpel blades with any of the metal implants. These samples were immediately placed in 10\% neutral buffered formalin in labeled collection tubes. Following fixation, the tissue samples were submitted for routine paraffin embedment. Paraffin blocks were sectioned at 4 microns, and the sections were placed on glass slides. Slides were stained with hematoxylin and eosin (H\&E) then examined under light microscopy to qualitatively determine the histopathology of the tissues. Evaluation of the slides included foreign body reaction (FBR, giant cells/macrophages in six 100x microscopic fields), metal particle count (particles $>3.3 \mu \mathrm{m}$ in six $100 \mathrm{x}$ fields), and inflammation (graded $0=$ not present to 2 = extensively present). Histological classifications were compared between tissue over single metal combinations ( $\mathrm{SS}+\mathrm{SS}, \mathrm{Ti}+\mathrm{Ti}$ ) and over each combination of different metals ( $\mathrm{SS}+\mathrm{Ti}$, SS + CC, $\mathrm{Ti}+\mathrm{CC})$ and between tissue over wire combinations and nonwire combinations.

2.5. Corrosion Analysis. Following removal of all tissue, the constructs were thoroughly rinsed in distilled water with care taken to avoid any metal contact with the constructs. They were then affixed to laminated sheets of the construct diagram and sterilized via ethylene oxide. Constructs were photographed then disassembled. Each component was again photographed and viewed, recording any discoloration or etching of the metal. 
Just prior to surgery and at 3, 6, 9, and 12 (just before to euthanizing) months post-op, each animal had $3 \mathrm{~mL}$ of blood drawn from an ear vein via a butterfly catheter. Blood was placed in metal free collection tubes (royal blue top) and the serum was extracted and stored frozen $\left(-20^{\circ} \mathrm{C}\right)$. Metal level analysis of the serum was not performed as there were only two animals at the 12-month survival period and the analysis was deemed to be not very meaningful for such a small sample size.

2.6. Data Collection and Analysis/Statistical Methods. Qualitative data was collected from the radiographic, visual observation, and histological evaluations as described above. The continuous dependent variables (FBR cells and number of metal particles in slides of overlying tissue) were compared between mixed versus single metal and wire versus other combinations using repeated measures analysis of variance (ANOVA). Chi-square comparisons of mixed versus single metal and wire versus other contacts were made for the histological parameter of inflammation. Significance was set at $P<0.05$. A sample size of $n=7$ was used due to the pilot nature of this project, so the power for the statistical analyses will be expectedly very low.

\section{Results}

3.1. Surgical Procedure. Four (one female and three male) animals had neurological dysfunction immediately postoperatively which did not resolve after two days. The first two surgeries had additional Ti supralaminar (most cephalad level) and SS infralaminar hooks attached bilaterally to the rods in two vertebral levels proximal to those outlined in Figure 1. Upon inspection of the spine following harvest, all four hooks in both animals had fractured and pulled through the laminae. In addition, a sublaminar wire technique was used in these first two animals in which the SS and CC double wires were passed through the sublaminar space then secured around the rods, leaving a double wire around the laminae. Since it was felt that these techniques resulted in neurologic deficit both times, all remaining cases were performed without hooks and using a single sublaminar wiring technique. Following these adjustments to the implant protocol, there were two additional neurologic insults that occurred in the immediate postoperative period. One deficit was clearly due to a pedicle screw placement impinging on the spinal cord, seen immediately on postoperative radiographs. The other neurological deficit was determined to be due to a CC wire that did not conform to the anterior surface of the lamina, extending over $1.5 \mathrm{~cm}$ into the canal. These four animals were euthanized and not included in further analyses.

Five months post-op, one female mini-pig developed a Group E Streptococcus (common in "streptococcal lymphadenitis of swine") surgical site infection, for which it was treated with aggressive irrigation and debridement of the wound under sedation (immediately and again one week later) with twice daily cleaning of the wound and a twenty-day course of antibiotics (Naxcel, $200 \mathrm{mg}$ IM daily). The infection
TABLE 1: Surgical parameters.

\begin{tabular}{lcc}
\hline & P12 & P2 \\
\hline & Male & Male \\
Levels instrumented & T12, T13, L1, L2, L3 & L1, L2, L3, L4, L5 \\
Length of surgery & $125 \mathrm{~min}$. & $140 \mathrm{~min}$. \\
Weight gain & $26 \%$ & $48 \%$ \\
Length increase & $6 \%$ & $19 \%$ \\
Implants in place & 12 months & 12 months \\
Blood loss & $10 \mathrm{cc}$ & $<20 \mathrm{cc}$ \\
\hline
\end{tabular}

TABLE 2: Radiographic parameters, kyphosis measured from lateral radiographs.

\begin{tabular}{lcc}
\hline & $\mathrm{P} 12$ & $\mathrm{P} 2$ \\
\hline Pre-op kyphosis & $25^{\circ}$ & $19^{\circ}$ \\
Immediate post-op kyphosis & $4^{\circ}$ & $0^{\circ}$ \\
3 months post-op & $23^{\circ}$ & $17^{\circ}$ \\
6 months post-op & $33^{\circ}$ & $13^{\circ}$ \\
9 months post-op & $25^{\circ}$ & $12^{\circ}$ \\
12 months post-op & $34^{\circ}$ & $11^{\circ}$ \\
After harvest & $29^{\circ}$ & $11^{\circ}$ \\
\hline
\end{tabular}

did not resolve, so the animal was euthanized almost 7 months following implant placement. This animal was also excluded from all further analyses.

Surgical times for the remaining two male animals were 125 minutes and 140 minutes, with blood loss of $<20 \mathrm{cc}$ in the two animals (Table 1). The recovery periods were unremarkable and animals were returned to regular pen and activity levels within two days. Body weight increased by 26 and $48 \%$ (from 49 and $40 \mathrm{~kg}$ pre-op to 61.5 and $59 \mathrm{~kg}$, resp.) and body length increased by 6 and 19\% (from 92.5 and $80 \mathrm{~cm}$ pre-op to 98 and $95 \mathrm{~cm}$, resp.) over the 12 months following surgery.

3.2. Radiographic Analysis. Radiographs taken immediately post-op showed appropriately placed implant constructs (Figure 2). All implants remained intact and in place for the full twelve months. No intervertebral fusion developed at any of the surgical levels. In the 3-month post-op X-rays, lucency was seen around all of the screws (right and left and proximal and distal) indicating that there was motion of the screws within the bone. Lucency remained the same or increased in the 6-, 9-, and 12-month post-op films; however, screws did not pull out (Figure 3). Pre-op X-rays of the surgical levels showed some kyphosis "naturally" present (19 and $\left.25^{\circ}\right)$ which was eliminated by placement of the implant construct (post-op kyphosis was $4^{\circ}$ kyphosis and $0^{\circ}$, Table 2). Kyphosis returned by the 3-month post-op films, with both animals returning to within $2^{\circ}$ of the pre-op sagittal contour. There was some evidence of vertebral body wedging created by posterior tethering of growth by the implant construct in one animal (P2). 


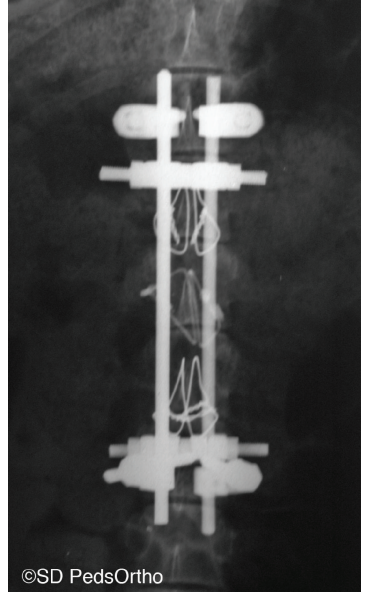

(a)

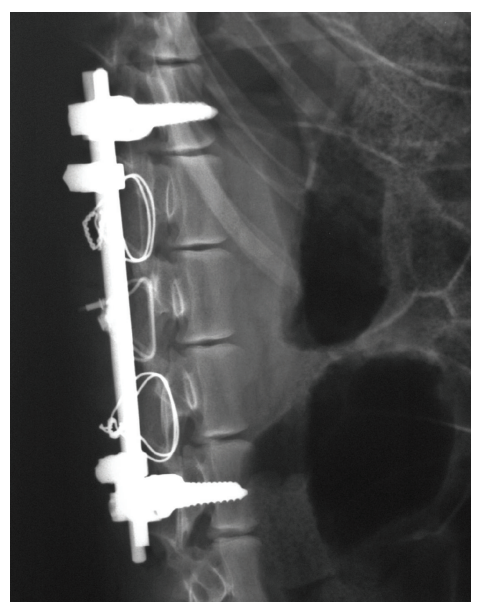

(b)

Figure 2: Dorsoventral (a) and lateral (b) radiographs taken immediately following placement of implant construct.

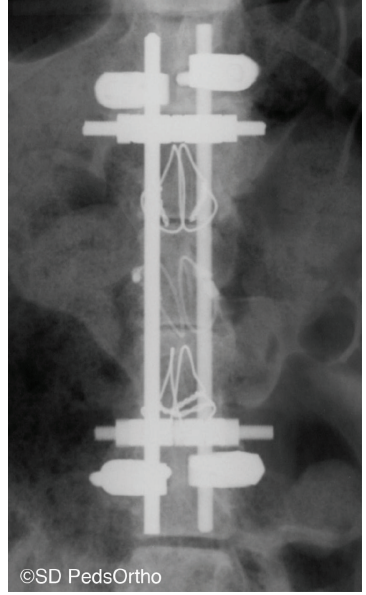

(a)

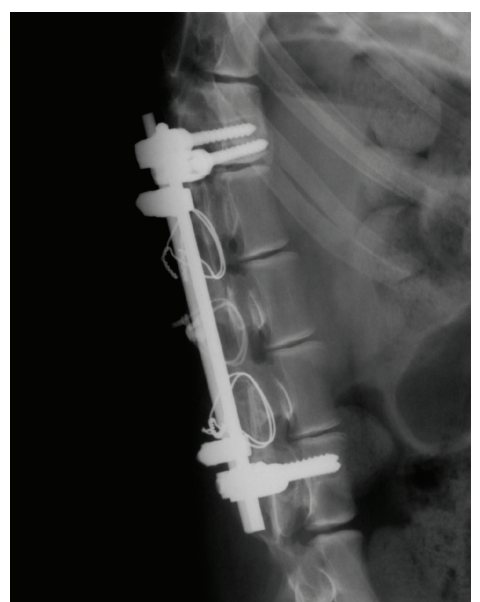

(b)

FIGURE 3: Dorsoventral (a) and lateral (b) radiographs taken 12 months following placement of implant construct (prior to harvest). Lucency around screws is especially seen on the lateral view, both in proximal and distal pair of screws.

Rod-wire distance measurements (average \pm stdev, adjusted for magnification) for the animals remaining in the study for the full 12 -month period $(n=2)$ were $10.35 \pm$ $0.48 \mathrm{~mm}$ for SS wires, $9.00 \pm 2.27$ for Ti cables, and $11.73 \pm 0.06$ for CC wires (Figure 4 shows an example). This demonstrated that the Ti cables protruded into the canal by 1 to $2 \mathrm{~mm}$ less than the SS and CC wires, conforming more readily to the posterior wall of the spinal canal. In the one single animal that did have a neurological deficit with single wires, rod-wire distances were 12.34 for SS wires, 11.81 for Ti cable, and 17.42 for $\mathrm{CC}$ wires. The one $\mathrm{CC}$ wire indicated with a solid arrow in Figure 4 was over $19 \mathrm{~mm}$.

3.3. Gross Observation. By gross observation, all implants and wires remained intact and in place. Muscle tissue over the implants for the two spines was generally pink and normal in appearance, with slight tissue discoloration noted over a few of the implants (P12: very little discoloration, P2: yellow coloring over the SS rod + Ti screw and SS rod + SS wire junctions and slight graying over the Ti rod + SS x-link junction). There was some "scarring" (white, glistening tissue) surrounding all metal components. No loose metal particles were detectable in any of the specimens by gross observation.

There was some scratching of the SS and Ti rods in P12, mainly with the Ti cable junction on the SS rod. However, there was no obvious discoloration of any of the implants from P12 or P2.

3.4. Histological Analysis. Figure 5 shows the typical appearance of histological samples including fibrosis, necrosis (pyknotic nuclei and necrotic debris), foreign body reaction (granuloma, giant multinucleated cells), and presence of metal particles. A summary of the histological data for single metal ( $\mathrm{SS}$ and $\mathrm{Ti}$ ) and mixed metal combinations is 


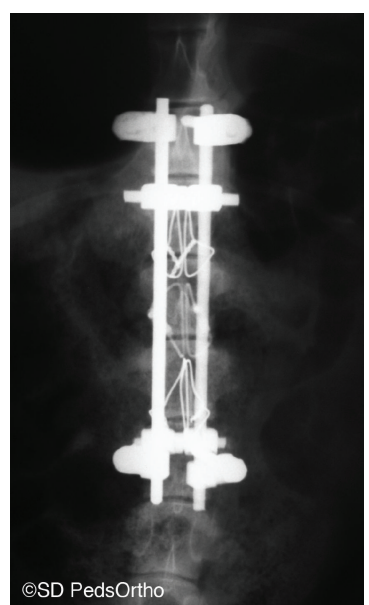

(a)

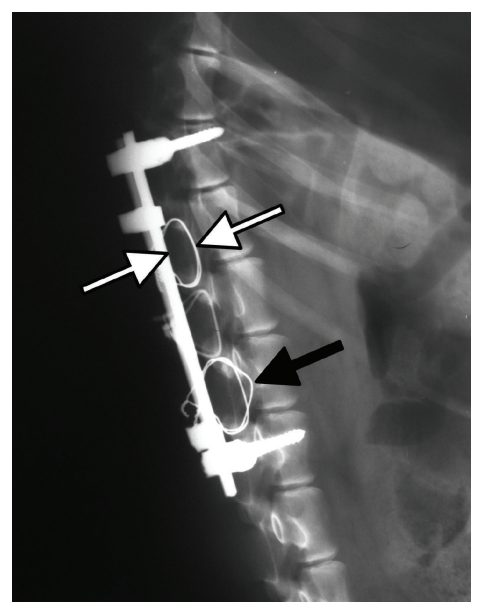

(b)

FIGURE 4: Dorsoventral (a) and lateral (b) radiographs taken immediately post-op. This animal sustained a neurological deficit post-op which did not resolve. An example of a rod-to-wire distance measurement is shown on the lateral radiograph as distance between two outlined arrows, and CC wire deemed to be the cause of the neurological deficit is shown by a solid black arrow.

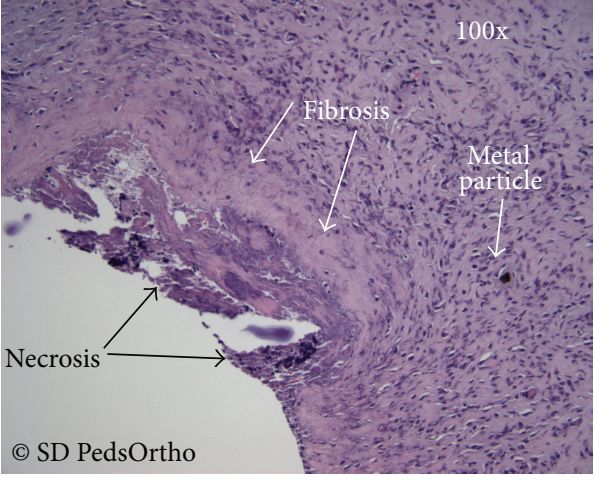

(a)

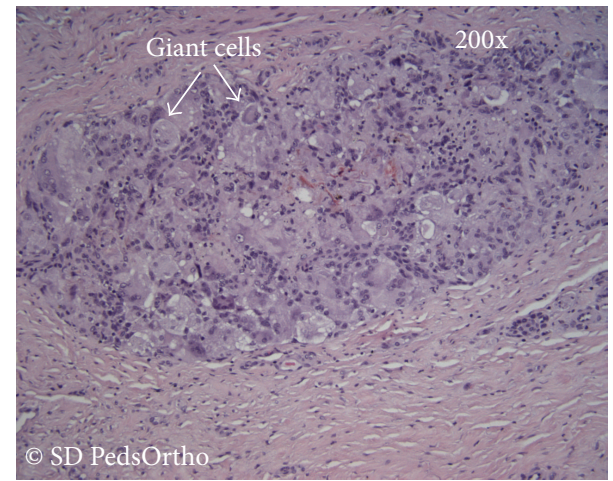

(b)

FIGURE 5: H\&E stained slides: (a) from tissue overlying a SS rod with SS crosslink junction showing fibrosis, necrosis, and a metal particle, (b) from tissue overlying a SS rod with CC sublaminar wire, giant cells showing foreign body reaction.

presented in Table 3. Histology of tissue over SS connections $(n=8)$ demonstrated $11.1 \pm 7.6$ FBR cells, $2.1 \pm 1.7$ metal particles, and moderate to extensive inflammation. When $\mathrm{Ti}$ components were linked $(n=6)$, tissue histology showed $6.3 \pm 3.8$ FBR cells, $5.2 \pm 6.7$ metal particles, and no to extensive inflammation ( $83 \%$ extensive). Tissue over mixed metal components $(n=22)$ had $14.1 \pm 12.6$ FBR cells and $13.4 \pm 27.8$ metal particles. Although it appears that there are more FBR cells and metal particles in mixed metal combinations than in SS or Ti alone, this is not significantly proven ( $P=0.347$, and 0.381 , resp.). Samples surrounding sublaminar wires/cables versus other combinations (Table 4) demonstrated FBR $(12.4 \pm 13.5$ versus $12.0 \pm 9.6$ cells, $P=$ $0.96)$, metal particles $(19.8 \pm 32.6$ versus $4.3 \pm 12.7, P=0.24)$, and inflammation (50\% versus $75 \%$ extensive, $P=0.12$ ). The number of metal particles in overlying tissue was on average 5 times higher in wire metal combinations, but this was not a significant finding $(P=0.241)$.
3.5. Corrosion Analysis. Figure 6 shows one set of components twelve months after implantation. All yellow, orange, or red discoloration is likely due to tissue remaining on the implants. We did not scrub the implants due to the risk of scratching the surfaces. No erosion of the rods is seen, with only some surface scratching at the SS rod to SS crosslink junction, mainly in one animal (P2). The Ti rod had darker discoloration at the metal junctions than the SS rod but was not scratched.

\section{Discussion}

Despite the fact that surgical techniques for sublaminar hook and wire/cable placement currently employed in the pediatric population for spinal deformity correction were performed in this mini-pig model by spine surgeons with many years of experience performing sublaminar wires, the first two cases resulted in neurological deficit. A revised technique was 
TABLE 3: Histological results of tissue overlying metal junctions comparing single metal and mixed metal combinations (values are average \pm standard deviation).

\begin{tabular}{lccc}
\hline & $\begin{array}{c}\text { SS } \\
(n=8)\end{array}$ & $\begin{array}{c}\text { Ti } \\
(n=6)\end{array}$ & $\begin{array}{c}\text { Mixed } \\
(n=22)\end{array}$ \\
\hline $\begin{array}{l}\text { Foreign body reaction } \\
\text { (number of cells in 6 100x fields) }\end{array}$ & $11.1 \pm 7.6$ & $6.3 \pm 3.8$ & $14.1 \pm 12.7$ \\
$\begin{array}{l}\text { Metal particles } \\
\text { (number of particles in 6 fields) }\end{array}$ & $2.1 \pm 1.7$ & $5.2 \pm 6.7$ & $13.4 \pm 27.8$ \\
$\begin{array}{l}\text { Inflammation (average score) } \\
(0=\text { not present, 2 }=\text { extensively present) }\end{array}$ & $1.8 \pm 0.4$ & $1.7 \pm 0.8$ & $1.6 \pm 0.6$ \\
\hline
\end{tabular}

TABLE 4: Histological results of tissue overlying metal junctions comparing wire and other types of combinations (values are average \pm standard deviation).

\begin{tabular}{lcc}
\hline & $\begin{array}{c}\text { Wire } \\
(n=12)\end{array}$ & $\begin{array}{c}\text { Other } \\
(n=24)\end{array}$ \\
\hline $\begin{array}{l}\text { Foreign body reaction } \\
\text { (number of cells in 6 100x fields) }\end{array}$ & $12.4 \pm 13.5$ & $12.0 \pm 9.6$ \\
$\begin{array}{l}\text { Metal particles } \\
\text { (number of particles in 6 fields) }\end{array}$ & $19.8 \pm 32.7$ & $4.3 \pm 12.7$ \\
$\begin{array}{l}\text { Inflammation (average score) } \\
(0=\text { not present, 2 }=\text { extensively present) }\end{array}$ & $1.8 \pm 0.4$ & $1.7 \pm 0.8$ \\
\hline
\end{tabular}

applied, which provided improved neurological outcomes. However, the Yucatan mini-pig was still found to be susceptible to neurological deficit when the sublaminar wires/cables do not conform well to the posterior canal. This was especially the case with use of CC wire, in which the surgeons found it much more difficult to precisely contour and control the shape due to the high yield strength of the metal. This shows how relatively stenotic and neurologically sensitive the Yucatan mini-pig is as a model for sublaminar wire placement. Sublaminar hooks were found not to be a viable technique in this animal model due to the fragile laminar bone and the forces applied as the spine returned to its normal kyphosis. Clearly, studying sublaminar wiring techniques for use in the clinical population using this animal model is not optimal.

Immediately post-op, the regular kyphotic contour of the lumbar spine was removed in all the animals as the spine was instrumented with straight rods. Within the first three months following surgery, most of the normal kyphotic contour returned as the spine returned to its natural position via flexion through the unfused intervertebral discs. This return of kyphosis was accomplished at the expense of screw loosening, as seen on radiographs. Sublaminar hooks, used in the first two animals, pulled out as the spine returned to its kyphotic contour resulting in vertebral fracture, whereas the pedicle screws loosened but did not pull out substantially, allowing a nontraumatic return of the normal kyphotic contour. Pedicle screws were therefore found to be a safer technique than hooks for vertebral fixation in this model that we have proposed to use to study corrosion. No fusion occurred over the 12-month survival period, allowing maximal opportunity for motion of the implant construct with possible related corrosion effects.
Corrosion in orthopedic implants has been correlated with decrease in implant integrity, tissue reaction, infection, and pain $[6,13,17-20]$. More specifically, corrosion due to micromotion in spine implants has been blamed for late onset pain and drainage from the instrumentation site. Wimmer and Gluch report on eight patients with radiographic lucency around pedicle screws, six of which had a discharging sinus and pain between 12 and 34 months post-op. Instrumentation was removed from these six patients, and overlying tissue was found to be necrotic and stained with metallosis. They theorize that micromotion between implant components causes metal debris, metal debris, resulting in a foreign body reaction, formation of a false membrane and subsequent late onset fluid drainage [21]. Likewise, Dubousset et al. attribute late onset infection to micromotion of the instrumentation [22]. However, Richards suspected late drainage following spinal instrumentation is caused by intraoperative seeding that remains subclinical for at least 12 months [23]. Likewise, Clark and Shufflebarger found that drainage appearing at least one year following surgery was a granulomatous reaction caused not by fretting corrosion but by the late activation of bacteria introduced at the time of surgery. They prolonged the culture time from 72 hours ( 1 of 10 cultures was positive) to 7 days (11 of 12 cultures were positive) [24]. More recently, Ho et al. reported that last onset infections in this population are likely due to many factors, including past medical history, use of blood transfusions, and not using a postoperative drain. Specifically, the number of anchor points or levels of instrumentation, which would correspond to the number of metal connections, was not associated with delayed infections [25]. In addition to corrosion resulting from micromotion, corrosion due to having two metals of different types in 
P2: implants in vivo for 12 months
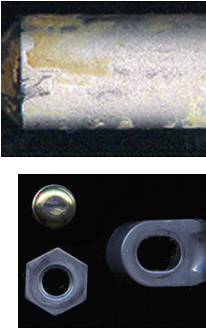
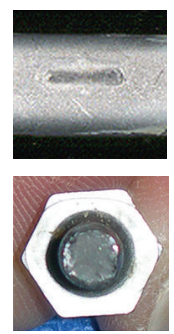
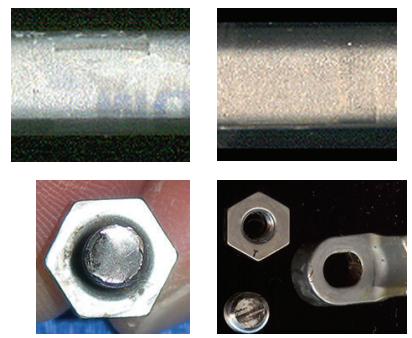
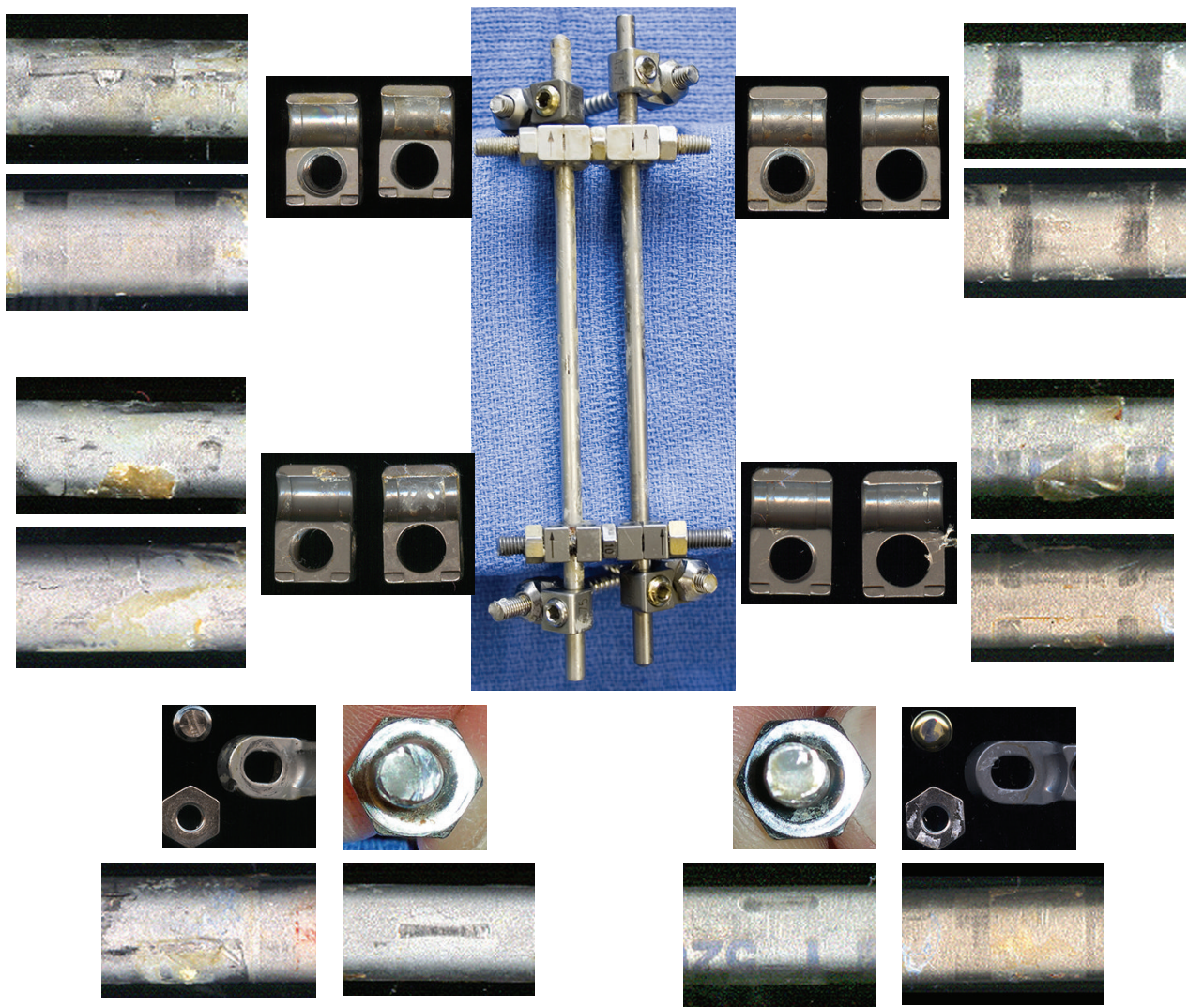

(C) SD PedsOrtho

FIGURE 6: Explanted components from one animal following twelve months in vivo. These are arranged in the same orientation as in Figure 1.

contact with each other has been shown to be a clinical problem in hip prostheses [18].

In the current in vivo study, there were no obvious or catastrophic tissue consequences resulting from the contact of differing metals in spinal implants in this animal model over a year. Tissue samples over the single metal combinations and mixed metal combinations had similar levels of foreign body reaction, metal particles, fibrosis, and inflammation. Also, no significant differences were found in overlying tissue response to wires versus other types of combinations in this preliminary study; however, there is a suggestion that wires moving over a rod produce more metal particles than fixed metal junctions, regardless of the type of metal wires or rod. Though it remains best to err on the side of caution, this study does not offer support that mixed metal combinations are any more dangerous, or cause a more severe physiological reaction at the tissue level, than combining components of the same metal.

At this time, most surgeons remain hesitant to combine stainless steel with titanium or cobalt chrome metal in orthopedic implants for fear of increased complication rates $[11,13]$. This study must be considered preliminary work and the lack of statistical differences noted is likely due to the small sample size and limited statistical power. In addition to the valuable, but limited, data on the effect of corrosion in a biological environment, valuable lessons have been learned regarding the limitation of this animal model to study spinal techniques including the fragile laminar bone that will not tolerate sublaminar hooks exerting substantial forces and the neurological sensitivity of this animal model to sublaminar 
wiring. Further study with greater numbers is needed to answer the clinical concern of safety when mixing metals in spinal constructs, and we hope these pilot data will inform others who may wish to perform such studies. In vivo study such as this is ultimately required, in addition to ASTM and ISO testing standards for in vitro testing [26], and is clinically relevant to surgeons who initially implant and often revise patients particularly with nonfusion implant systems such as distraction based growing rods or growth guidance based procedures such as Shilla or Luque trolley.

\section{Conflict of Interests}

The authors declare that there is no conflict of interests regarding the publication of this paper.

\section{Acknowledgment}

DePuy Spine, Inc. supplied all implants and support for the research study.

\section{References}

[1] J. J. Jacobs, J. L. Gilbert, and R. M. Urban, "Corrosion of metal orthopaedic implants," Journal of Bone and Joint Surgery A, vol. 80, no. 2, pp. 268-282, 1998.

[2] J. Black, "Does corrosion matter?" Journal of Bone and Joint Surgery B, vol. 70, no. 4, pp. 517-520, 1988.

[3] W. J. Gaine, S. M. Andrew, P. Chadwick, E. Cooke, and J. B. Williamson, "Late operative site pain with isola posterior instrumentation requiring implant removal: infection or metal reaction?" Spine, vol. 26, no. 5, pp. 583-587, 2001.

[4] U. Vieweg, D. van Roost, H. K. Wolf, C. A. Schyma, and J. Schramm, "Corrosion on an internal spinal fixator system," Spine, vol. 24, no. 10, pp. 946-951, 1999.

[5] L. Aulisa, A. di Benedetto, A. Vinciguerra, and P. TranquilliLeali, "Corrosion of the Harrington's instrumentation and biological behaviour of the rod-human spine system," Biomaterials, vol. 3, no. 4, pp. 246-248, 1982.

[6] S. Cook, M. Asher, S.-M. Lai, and J. Shobe, "Reoperation after primary posterior instrumentation and fusion for idiopathic scoliosis: toward defining late operative site pain of unknown cause," Spine, vol. 25, no. 4, pp. 463-468, 2000.

[7] Y. Mochida, T. W. Bauer, H. Nitto, H. E. Kambic, and G. F. Muschler, "Influence of stability and mechanical properties of a spinal fixation device on production of wear debris particles in vivo," Journal of Biomedical Materials Research, vol. 53, no. 3, pp. 193-198, 2000.

[8] H. Senaran, P. Atilla, F. Kaymaz, E. Acaroglu, and A. Surat, "Ultrastructural analysis of metallic debris and tissue reaction around spinal implants in patients with late operative site pain," Spine, vol. 29, no. 15, pp. 1618-1623, 2004.

[9] B. W. Cunningham, C. M. Orbegoso, A. E. Dmitriev et al., "The effect of spinal instrumentation particulate wear debris: an in vivo rabbit model and applied clinical study of retrieved instrumentation cases," Spine Journal, vol. 3, no. 1, pp. 19-32, 2003.

[10] N. J. Hallab, B. W. Cunningham, and J. J. Jacobs, "Spinal implant debris-induced osteolysis," Spine, vol. 28, no. 20, pp. S125-S138, 2003.
[11] J. S. Kirkpatrick, R. Venugopalan, P. Beck, and J. Lemons, "Corrosion on spinal implants," Journal of Spinal Disorders and Techniques, vol. 18, no. 3, pp. 247-251, 2005.

[12] M. L. Villarraga, P. A. Cripton, S. D. Teti et al., "Wear and corrosion in retrieved thoracolumbar posterior internal fixation," Spine, vol. 31, no. 21, pp. 2454-2462, 2006.

[13] K. C. Zartman, G. C. Berlet, C. F. Hyer, and J. R. Woodard, "Combining dissimilar metals in orthopaedic implants: revisited," Foot \& Ankle Specialist, vol. 4, no. 5, pp. 318-323, 2011.

[14] P. J. Høl, A. Mølster, and N. R. Gjerdet, "Should the galvanic combination of titanium and stainless steel surgical implants be avoided?" Injury, vol. 39, no. 2, pp. 161-169, 2008.

[15] H. Serhan, M. Slivka, T. Albert, and S. D. Kwak, "Is galvanic corrosion between titanium alloy and stainless steel spinal implants a clinical concern?" Spine Journal, vol. 4, no. 4, pp. 379-387, 2004.

[16] L. C. Lucas, P. Dale, R. Buchanan, Y. Gill, D. Griffin, and J. E. Lemons, "In vitro vs in vivo corrosion analyses of two alloys," Journal of Investigative Surgery, vol. 4, no. 1, pp. 13-21, 1991.

[17] K. A. Thomas, S. D. Cook, A. F. Harding, and R. J. Haddad Jr., "Tissue reaction to implant corrosion in 38 internal fixation devices," Orthopedics, vol. 11, no. 3, pp. 441-451, 1988.

[18] J. L. Gilbert, C. A. Buckley, and J. J. Jacobs, "In vivo corrosion of modular hip prosthesis components in mixed and similar metal combinations. The effect of crevice, stress, motion, and alloy coupling," Journal of Biomedical Materials Research, vol. 27, no. 12, pp. 1533-1544, 1993.

[19] B. F. Shahgaldi, F. W. Heatley, A. Dewar, and B. Corrin, "In vivo corrosion of cobalt-chromium and titanium wear particles," Journal of Bone and Joint Surgery B, vol. 77, no. 6, pp. 962-966, 1995.

[20] L. C. Lucas, R. A. Buchanan, and J. E. Lemons, "Investigations on the galvanic corrosion of multialloy total hip prostheses," Journal of Biomedical Materials Research, vol. 15, no. 5, pp. 731$747,1981$.

[21] C. Wimmer and H. Gluch, "Aseptic loosening after CD instrumentation in the treatment of scoliosis: a report about eight cases," Journal of Spinal Disorders, vol. 11, no. 5, pp. 440-443, 1998.

[22] J. Dubousset, H. Shuffleberger, and D. Wenger, "Late infection with CD instrumentation," Orthopaedic Transactions, vol. 18, article 121, 1994.

[23] S. Richards, "Delayed infections following posterior spinal instrumentation for the treatment of idiopathic scoliosis," Journal of Bone and Joint Surgery A, vol. 77, no. 4, pp. 524-529, 1995.

[24] C. E. Clark and H. L. Shufflebarger, "Late-developing infection in instrumented idiopathic scoliosis," Spine, vol. 24, no. 18, pp. 1909-1912, 1999.

[25] C. Ho, D. J. Sucato, and B. S. Richards, "Risk factors for the development of delayed infections following posterior spinal fusion and instrumentation in adolescent idiopathic scoliosis patients," Spine, vol. 32, no. 20, pp. 2272-2277, 2007.

[26] M. Hahn, R. Nassutt, G. Delling, O. Mahrenholtz, E. Schneider, and M. Morlock, "The influence of material and design features on the mechanical properties of transpedicular spinal fixation implants," Journal of Biomedical Materials Research, vol. 63, no. 3, pp. 354-362, 2002. 


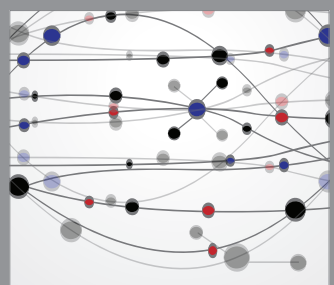

The Scientific World Journal
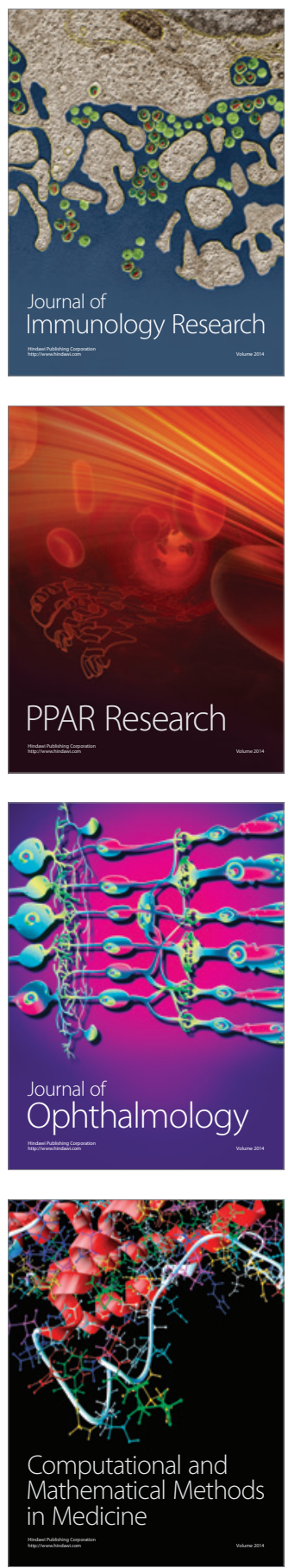

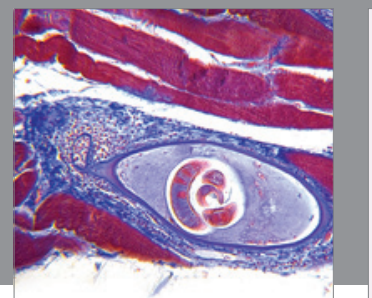

Gastroenterology

Research and Practice
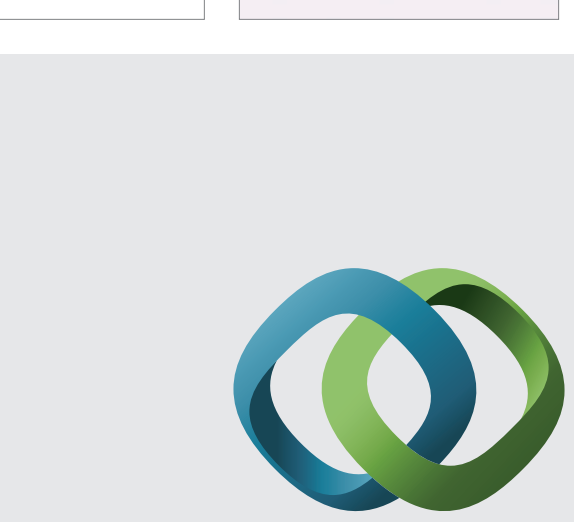

\section{Hindawi}

Submit your manuscripts at

http://www.hindawi.com
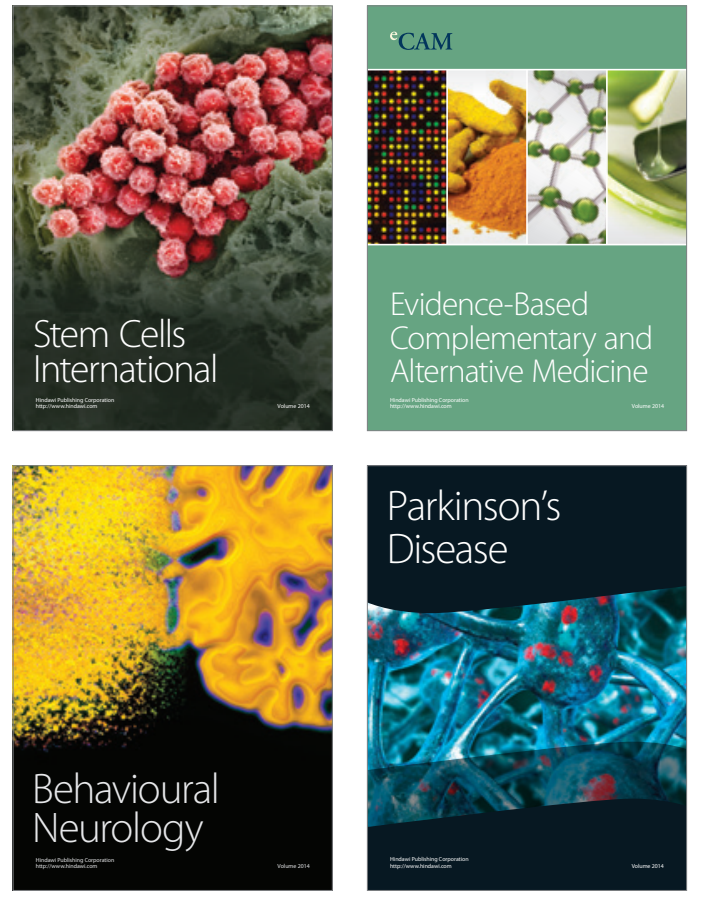
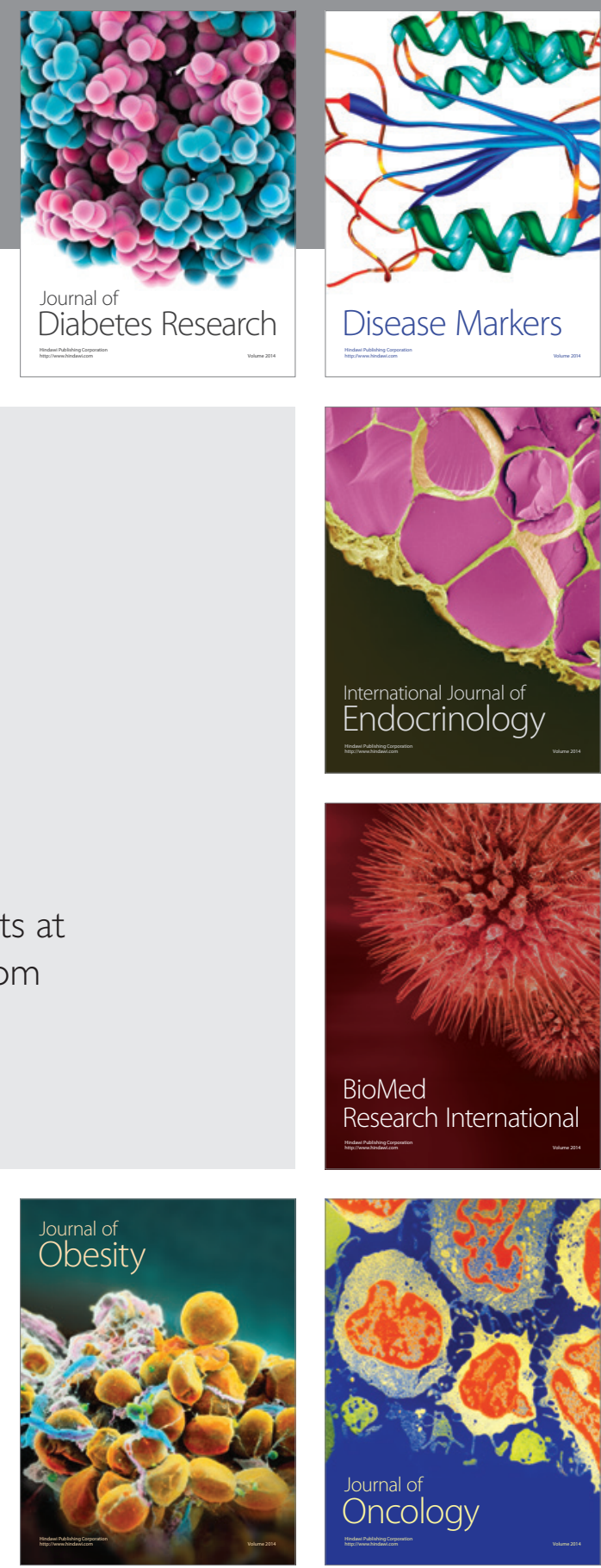

Disease Markers
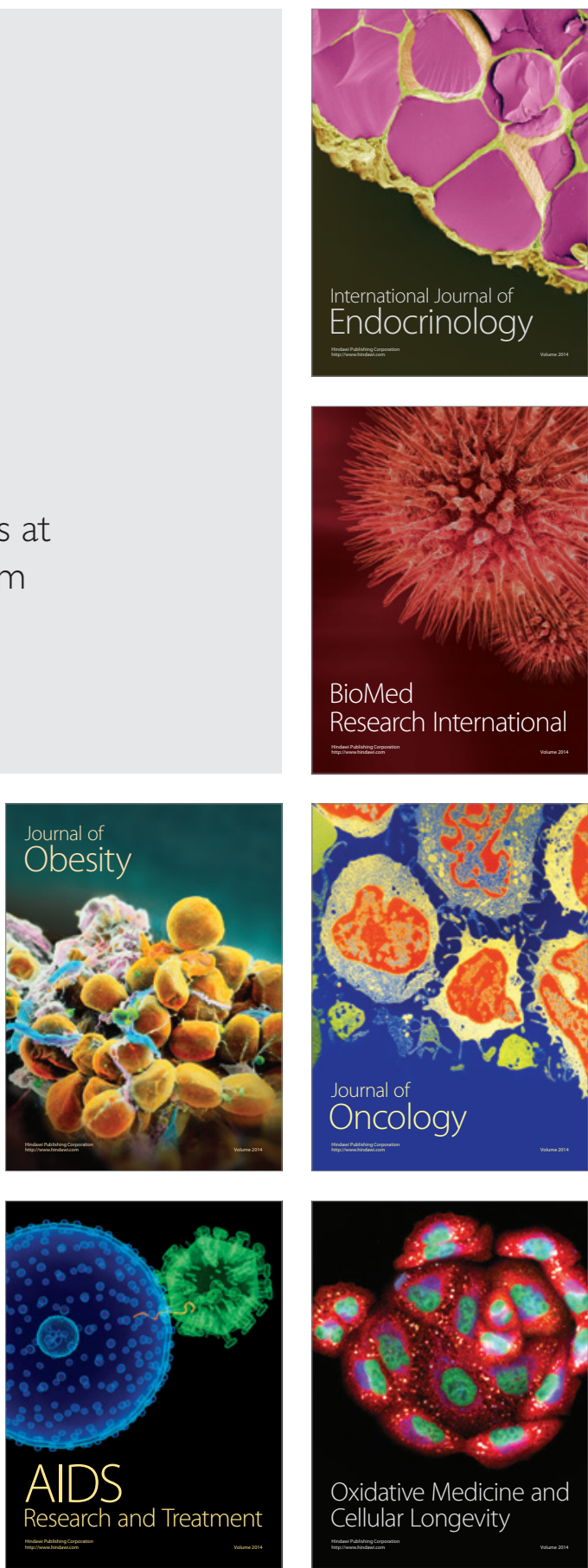